\title{
Identificação, Análise e Priorização de Requisitos de Aplicações Gamificadas para Apoio ao Ensino de Crianças com Síndrome de Down
}

\section{Title: Identification, Analysis and Prioritization of Requirements for Gamified Applications to Support the Teaching of Children with Down's Syndrome}

Igor V. de Souza

Departamento de Sistemas e Computação, Universidade Federal de Campina Grande, Brasil. igorvieira@copin.ufcg.edu.br

\section{S. A. Ghirello-Pires}

Departamento de Estudos Linguísticos e Literários, Universidade Estadual do Sudoeste da Bahia, Brasil. carlaghipires@hotmail.com

\author{
J. Antão B. Moura \\ Departamento de Sistemas e \\ Computação, Universidade Federal \\ de Campina Grande, Brasil. \\ antao@dsc.ufcg.edu.br
}

Uwe Terton Engage Research Lab, University of the Sunshine Coast, Australia. uterton@usc.edu.au

\begin{abstract}
Joaquim J.C. M.Honório Departamento de Sistemas e Computação, Universidade Federal de Campina Grande, Brasil. joaquimhonorio@copin. ufcg.edu.br
\end{abstract}

\section{Resumo}

A síndrome de Down (SD) é a causa genética mais comum de deficiência intelectual no mundo, exigindo maior atenção, principalmente, no que diz respeito aos processos de alfabetização. Apesar dos esforços de trabalhos anteriores, ainda são escassos estudos que auxiliem no processo de alfabetização e aquisição de linguagem e que proporcionem simultaneamente educação e diversão. Este trabalho apresenta os resultados de uma pesquisa que visa elicitar e validar requisitos que podem nortear o desenvolvimento de softwares gamificados que auxiliem no processo de alfabetização e aquisição da linguagem para crianças com SD, de forma lúdica. Para tanto, o estudo elicitou os requisitos a partir da revisão de literatura, análise de produtos de softwares e entrevistas com especialistas e pessoas com SD. Os resultados sugerem indícios de que os requisitos encontrados podem auxiliar o processo de alfabetização na SD. Este trabalho contribui com o desenvolvimento de aplicações para aquisição da linguagem e alfabetização em crianças com SD, considerando que ele fornece informações sobre requisitos, suas classes e suas validações, servindo futuramente como um guia para o desenvolvimento de softwares gamificados. Palavras-Chave: Gamificação; Síndrome de Down; Engenharia de Requisitos; Educação Especial; Aquisição da linguagem; Alfabetização.

\begin{abstract}
Down syndrome (DS) is the most common genetic cause of intellectual disability in the world, requiring more attention, especially, in relation to literacy processes. Despite the efforts of previous work, there are still few studies that help in the process of literacy and language acquisition and that simultaneously provide education and fun. This work presents the results of a research that aims to elicit and validate requirements that can guide the development of gamed software that assist in the process of literacy and language acquisition for children with DS in a playful way. Therefore, the study elicited the requirements from literature review, software product analysis and interviews with experts and people with DS. The results suggest that the requirements found may give the expected support to
\end{abstract}

Cite as: Souza, I. V., Moura, J. A. B., Honório, J. J. C.M., Ghirello-Pires, C. S. A. \& Terton, U. (2019). Identification, Analysis and Prioritization of Requirements for Gamified Applications to Support the Teaching of Children with Down's Syndrome (Identificação, Análise e Priorização de Requisitos de Aplicações Gamificadas para Apoio ao Ensino de Crianças com Síndrome de Down). Brazilian Journal of Computers in Education (Revista Brasileira de Informática na Educação - RBIE), 27(1), 154-174. DOI: 10.5753/RBIE.2019.27.01.154 
the literacy of people with DS. This work contributes to the development of applications for language acquisition and literacy in children with $D S$, considering that it provides information about requirements, their classes and their validations, working, in future, as a guide for the development of such applications.

Keywords: Gamification; Literacy; Language Acquisition; Requirements Engineering; Down's Syndrome; Special Education.

\section{Introdução}

A síndrome de Down (SD) é a causa genética mais comum de deficiência intelectual no mundo, acontecendo com uma proporção de, aproximadamente, um caso para cada 700 nascimentos vivos (Martin, 2009). A partir deste número e de estimativas do Movimento Down (www.movimentodown.org.br) para 2013, presume-se que existam mais de 300 mil pessoas com $\mathrm{SD}$ no Brasil. As pessoas com SD apresentam deficiência em vários canais sensoriais e motores, com limitações em habilidades como a memória, a cognição e a comunicação (Feng et al., 2008), tendo, de acordo Schwartzman (1999) e Cunningham (2008), a linguagem como a área mais afetada e com maior atraso no desenvolvimento.

Alguns estudos sugerem que o processo de estimulação da linguagem na SD deve ser feito intensivamente desde os primeiros meses de vida da criança a fim de evitar que as dificuldades apresentadas em articular a fala e adquirir a linguagem persistam até a fase adulta (Ghirello-Pires, 2016; Roberts, 2007; Martin, 2009). Assim sendo, algumas práticas pedagógicas como a utilização de jogos, brincadeiras, canções e atividades orais e motoras são empregadas, atualmente, para auxiliar no processo de aquisição da linguagem nessas crianças (Ghirello-Pires, 2016). Porém, tais práticas, em sua maioria, ainda são feitas de forma manual pelos especialistas e terapeutas, principalmente, devido à escassez de aplicativos de software que atendam, em específico, às necessidades das crianças com SD. Fatores como o excesso de repetições, o desconforto e a monotonia na realização de alguns exercícios podem desmotivar essas crianças a se manterem engajadas com tais procedimentos pedagógicos, levando-as, consequentemente, à dispersão na aprendizagem e diminuindo, assim, o rendimento.

Dessa forma, considera-se necessária a utilização de aplicativos educacionais que permitam contornar essas dificuldades, potencializando os procedimentos pedagógicos para que as crianças com SD se sintam engajadas e motivadas para realizar as atividades propostas pelos terapeutas e profissionais, para um maior aprendizado e rendimento. Embora já existam estudos que abordem o uso de software educacionais como jogos sérios (Farias et al., 2013; Buzzi et al., 2016; Brandão e Joselli, 2015) para estimular o processo cognitivo e motor das crianças com SD, ainda faz-se necessário uma abordagem voltada para o processo de alfabetização, em especial, para o processo de aquisição da linguagem, que atenda às necessidades dessas crianças e que possibilite um aprendizado interativo e divertido tanto dentro quanto fora do aplicativo.

Com o crescente aumento do uso da gamificação na área de educação nos últimos anos, vem tornando-se evidente que, quando usada corretamente, a gamificação consegue não só auxiliar o processo e os resultados da aprendizagem, como também motivar e dar suporte ao estudante. Por isso, acredita-se que o uso de aplicações gamificadas, de realidade alternada - ou seja, aplicativos de software com características de jogos multimídia com o objetivo misto de educação e entretenimento, alternando experiências no mundo real e virtual - pode, além de facilitar a criação de atividades pelos profissionais, contribuir para aprimorar a interação das crianças com SD com práticas educacionais embutidas em tais aplicações, tornando estas práticas mais atraentes e engajadoras para o processo de aprendizagem. Entretanto, ainda são raros os estudos sobre o uso de gamificação com crianças com $\mathrm{SD}$, especialmente, os relacionados ao processo de aquisição da linguagem e alfabetização. 
Este artigo trata do estudo de requisitos para aplicações gamificadas que deem suporte à alfabetização de crianças com $\mathrm{SD}$, acelerando e melhorando os processos de aquisição e funcionamento da linguagem (tais aplicações são aqui chamadas de $g$-apps $S D$ ). Esta pesquisa exploratória busca identificar e validar as classes de tais requisitos para propor e ajustar um conjunto inicial de requisitos. $O$ processo de validação usa entrevistas e questionários com pais, especialistas e pessoas com SD no Brasil e na Austrália. A validação busca indícios de que g-apps $S D$ que venham a incorporar os requisitos resultantes possam dar o suporte esperado à alfabetização de pessoas com SD, além de apoiar o projeto da arquitetura e o planejamento da evolução de versões de $g$-apps $S D$, complementando trabalhos sobre o assunto.

O conteúdo restante deste artigo está organizado da seguinte forma: A Seção 2 examina brevemente a literatura e os produtos acadêmicos sobre aplicações gamificadas para crianças com SD; A Seção 3 apresenta a metodologia utilizada para elicitação e validação dos requisitos necessários para o desenvolvimento de g-apps SD; A Seção 4 apresenta os resultados iniciais da pesquisa em andamento para elicitação de requisitos para g-apps SD. A Seção 5 apresenta os resultados obtidos durante o processo de validação das classes e requisitos. A Seção 6 traz as conclusões e sugestões para futuras pesquisas.

\section{Trabalhos Relacionados}

A Aprendizagem Baseada no Jogo (GBL - Game-Based Learning) usa conceitos e tecnologia de jogos para ensinar e motivar um determinado público-alvo a aprender. A GBL está se tornando cada vez mais comum na área de educação e alguns dos fatores que contribuem para isso vem, como Shih, Squire e Lau (2010) afirmam, da falta de limitações de assuntos ou cursos para o uso desta prática e que, com o desenvolvimento de tecnologias de comunicações pervasivas, os alunos têm a possibilidade para jogar e aprender em uma comunidade social. De modo que, quando bem aplicado, não só é possível aumentar a motivação dos alunos como também melhorar o seu aprendizado. A gamificação de aplicativos educacionais, assim como GBL, faz bom uso desses fatores.

Uma revisão da literatura especializada feita por Caponetto et al (2014), apontou que o uso da gamificação em educação se dá devido à sua capacidade de auxiliar o aprendizado, promovendo atitudes, atividades e comportamentos desejáveis por meio de abordagens participativas, da colaboração e competição amigável, do estudo autoguiado, da facilitação e efetividade das avaliações, da integração de abordagens exploratórias para a aprendizagem e do fortalecimento da criatividade e retenção dos alunos. Contudo, ainda são raras as abordagens gamificadas para o ensino de pessoas com necessidades especiais, principalmente, com SD.

Entre as exceções estão: o trabalho de Colpani e Homem (2015), em que é proposto um novo framework educacional com realidade virtual e gamificação para auxiliar na aprendizagem de crianças com deficiência intelectual. Os autores usam conceitos de realidade aumentada para facilitar o processo de adaptação e aprendizado. Entretanto, a limitação do conjunto de requisitos para o framework e o seu pioneirismo requer novas pesquisas e experimentos para verificar a efetividade deste framework na prática; o Moviletrando (Farias et al., 2013), um jogo sério que busca estimular as funções motoras e cognitivas das crianças com $\mathrm{SD}$, ao mesmo tempo que auxilia no processo de alfabetização. Um ponto forte deste trabalho é a ideia de fazer as crianças se movimentarem em um jogo de realidade virtual para ensiná-las as letras do alfabeto. Porém, apesar desse estudo ser voltado para o processo de alfabetização, ele não considera o processo de aquisição da linguagem oral e escrita nas crianças; outros jogos sérios que tentam estimular o processo cognitivo, a memória e a sensibilização fonológica em crianças com SD no Brasil, incluem o Jecripe (Brandão et al., 2010) e Jecripe 2 (Brandão \& Joselli, 2015). Contudo, nenhum dos dois foca no processo de alfabetização. 
Estudos relacionados ao uso de software e ferramentas educacionais - não necessariamente gamificadas - para facilitar o aprendizado e estimular o processo cognitivo no contexto SD, incluem o de Fernández-López et al (2013) e o de Campigotto, Mcewen e Epp (2013). Estes trabalhos tratam de dispositivos móveis para auxiliar na aprendizagem de crianças com SD, prendendo a atenção e reduzindo as dificuldades de focar em estímulos particulares. Todavia, devido ao fato de que em ambos os estudos não foram utilizados softwares voltados, em específico, para crianças com SD, algumas necessidades especiais importantes de usabilidade e acessibilidade que essas crianças possuem podem não ter sido consideradas, deixando espaço para análises mais aprofundadas sobre $\mathrm{o}$ assunto.

Há também estudos sobre o uso de ferramentas tangíveis para auxiliar na alfabetização e no desenvolvimento de habilidades de leitura em crianças com SD, como o de Jadan-Guerrero et al (2015) e o de Haro, Santana and Magaña (2012). Nesses estudos, as ferramentas tangíveis são apresentadas como uma forma de reduzir as consequências do déficit de atenção, tornando o aprendizado mais divertido e interativo. Porém, os estudos apresentam poucos resultados estatísticos sobre o impacto dessas ferramentas no aprendizado de crianças com SD. Assim sendo, no presente trabalho é apresentado e discutido os resultados preliminares de uma investigação para identificar requisitos de g-app $S D$ que deem suporte à alfabetização de crianças com SD, acelerando e melhorando os processos de aquisição e funcionamento da linguagem (Português do Brasil).

\section{Metodologia para elicitação e validação de requisitos}

A Questão de Pesquisa (QP) que este trabalho endereça é "O conjunto de requisitos elicitados para uma aplicação de software gamificada para usuários com SD ( $g$-app SD) favorece a alfabetização de crianças com síndrome de Down (SD) de maneira eficiente e eficaz"? Assumese que a QP terá sido respondida afirmativamente se os atores envolvidos no processo de alfabetização de crianças com SD declararem que os requisitos são úteis para que as atividades de preparação, apresentação e fixação de lições sejam bem-sucedidas e eficientes em termos de tempo investido, engajamento e aceleração da curva de aprendizagem. Aqui, os atores de interesse são, além das próprias pessoas com $\mathrm{SD}$, fonoaudiólogos, pedagogos, linguistas, psicólogos, autores, professores, instrutores, monitores, designers de jogos, parentes e pessoas que assistem, produzem, aplicam ou utilizam material para a alfabetização na SD. A QP será colocada para uma amostra de atores na etapa de validação da metodologia adotada.

A metodologia para elicitar e validar os requisitos segue um modelo ágil (Larman, 2004) e iterativo, com os atores funcionando como clientes. Nesse modelo foi agregada a prática de Design Participativo (DP), também conhecido como Co-Design, (Camargo \& Fazani, 2014) em que os clientes são envolvidos no processo de design e desenvolvimento para garantir que o produto final seja mais eficiente e adequado ao usuário, tornando-o mais acessível e usável. Essa prática centrada no usuário, ao permitir que os atores/clientes participem durante o ciclo de desenvolvimento do software, possibilita atender melhor às necessidades do cliente e pode ser vista como uma abordagem mais focada nos processos e procedimentos que levam ao resultado (Mothu, 2017). Dessa forma, levando-se em consideração os conceitos abordados, a metodologia utilizada neste trabalho foi estruturada em 8 etapas:

i. Coletar requisitos de indivíduos com SD e seus parentes para software educacional e jogos.

ii. Adicionar à coleta acima, requisitos fornecidos por profissionais atuantes em SD e em design de jogos, a partir de suas percepções de necessidades de usuários e de suas experiências profissionais com ferramentas de software. 
iii. Acrescentar requisitos extraídos de análise e uso de produtos de software educacional, jogos e ferramentas para autoria, apresentação de lições e entretenimento para público em geral ou para pessoas com SD, em especial. Produtos de particular interesse para análise são os que envolvem a estimulação dos processos cognitivos e do aprendizado dentro do contexto de educação.

iv. Complementar o conjunto com requisitos elicitados da literatura sobre software educacional em geral ou gamificado para SD. Publicações sobre aplicações de software que fazem uso de objetos tangíveis, de sistemas de tutoria online e de jogos sérios são alguns exemplos de fontes bibliográficas para o levantamento de requisitos.

v. Analisar conjunto resultante para consolidar requisitos semanticamente equivalentes, mas com diferentes sintaxes. Apenas um requisito equivalente deve restar no conjunto.

vi. Agrupar os requisitos em classes para efeito de separação de domínios no projeto e implementação do software.

vii. Consultar atores para: especificar requisitos adicionais (voltar às etapas v e vi); adequar requisitos para atividades de alfabetização e aquisição da linguagem (Português do Brasil) de crianças com SD; e, priorizar as classes de requisitos no conjunto resultante segundo a importância para essas atividades.

viii. Validar o conjunto consolidado de classes e requisitos com os atores, em busca de responder à Questão de Pesquisa. Para expandir ou refinar o conjunto de requisitos, repetir as etapas acima em novo ciclo de ajustes.

Deve-se notar que as oito etapas da metodologia não precisam ser sequenciais e nem seguir a ordem acima, já que as quatro primeiras podem ser simultâneas. As etapas i) a vi) produzem um conjunto de requisitos genéricos para software educacional gamificado para SD; a vii) adequa os requisitos para o contexto de alfabetização e aquisição da linguagem; a viii) consolida as classes/requisitos em um conjunto ordenado, ou seja, priorizados, os quais servirão para guiar a evolução de versões de $g$-apps $S D$, transformando o esforço de pesquisa no projeto de $g$-apps $S D$ em ofertas práticas de software cujo uso criará mais caminhos, em termos de feedback pelo público com SD, para essa pesquisa. Essas etapas podem ser melhor observadas na Figura 1, onde um fluxograma apresenta o passo a passo da metodologia.

Os estudos de validação (priorização) são realizados nas etapas vii e viii. A priorização é importante por dar suporte a decisões sobre o perfil e a quantidade de recursos que devem ser alocados para pesquisa e desenvolvimento da aplicação. Os clientes são a parte central dessa priorização. Suas opiniões e votos orientam o design e o desenvolvimento de g-apps $S D$, assim como eles "deveriam" fazer em outras aplicações de software. Ao priorizar as classes de requisitos, é possível atribuir diferentes pesos para os votos (priorização) de clientes individuais (validadores) para refletir as suas experiências com SD, como adotar uma soma ponderada das prioridades, como a apresentada na equação 1.

$$
P_{\text {Geral }}^{C_{i}}=\sum_{\text {Ator }=1}^{T_{\text {Atores }}}\left(W_{\text {Ator }} * P_{\text {Ator }}^{C_{i}}\right)
$$

Onde $P_{G e r a l}^{C_{i}}$ é a prioridade geral da classe de requisitos $i ; w_{\text {Ator }}$ é o peso da opinião de Ator; $P_{A t o r}^{C_{i}}$ é a opinião (prioridade ou ordem de classificação) do Ator para a classe $i$, sendo que $1 \leq$ $P_{A t o r}^{C_{i}} \leq n$ e $n$ o número total de classes; e, $T_{\text {Atores }}$ é o número total de atores. Assume-se que $0 \leq$ $w_{\text {Ator }} \leq 1$ e $\sum_{\text {Ator }=1}^{T_{\text {Atores }}}\left(W_{\text {Ator }}\right)=1$. Além disso, por se tratar de uma metodologia baseada em Design Participativo e, principalmente, devido ao caráter exploratório deste estudo, foi feita a atribuição para todos os atores $w_{\text {Ator }}=1 / T_{\text {Atores }}$, isto é, que as opiniões de todos os atores tem pesos iguais. Esta atribuição é importante para que todos os atores se sintam conectados ao design do projeto e 
se sintam parte dele. Para tanto, é interessante que os atores entendam que suas opiniões e experiências serão refletidas no produto final desde que sejam factíveis.

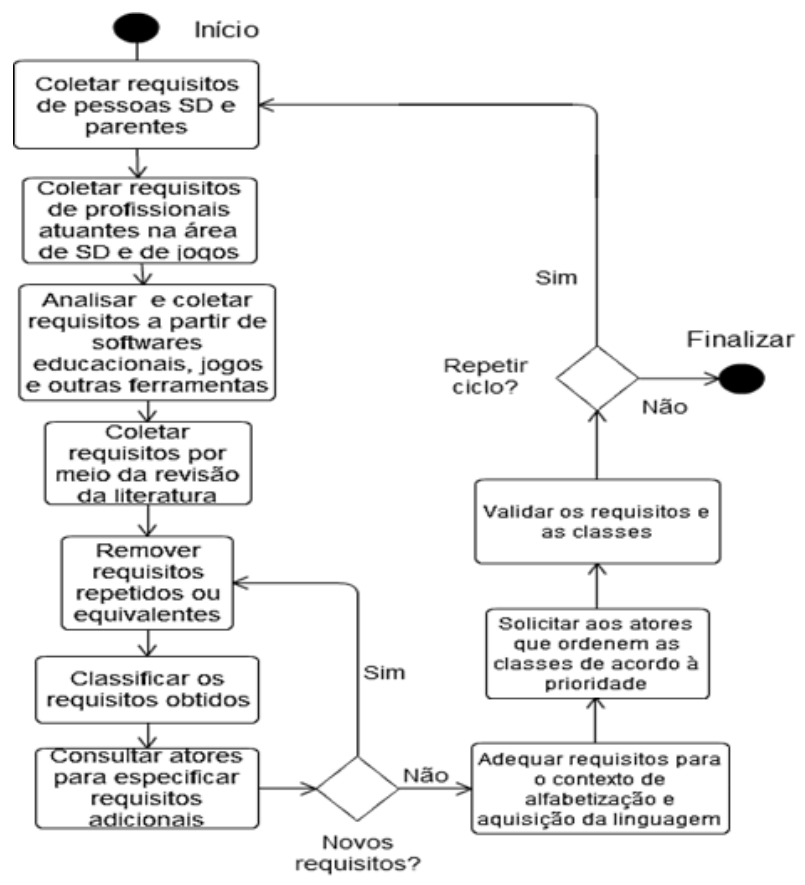

Figura 1: Metodologia proposta para o projeto e implementação g-apps $S D$

Uma vez que a engenharia de requisitos (Pohl, 2010) para um software assenta-se em um modelo do sistema alvo e que, por sua vez, a modelagem do sistema depende das suas características evolutivas e de percepções e preferências do modelador, pode-se argumentar que um conjunto de requisitos definitivo e completo é ilusório. Além disto, os esforços de pesquisa e desenvolvimento reportados neste artigo são recentes, tendo sido concluído um primeiro ciclo da metodologia para gerar um conjunto inicial de classes e requisitos. Este conjunto inicial, todavia, já se presta para direcionar e priorizar o desenvolvimento de atributos e funções de versões incipientes, porém úteis, de software-ferramentas para apoio à alfabetização e aquisição de linguagem de crianças com SD.

\section{Conjunto inicial de classes e requisitos para jogos SD}

É importante destacar que embora existam requisitos genéricos, como autenticação de login de usuário, que possam ser aplicados a diversos contextos além dos relacionados às necessidades de pessoas com SD, eles não fazem parte do escopo deste trabalho, assim como também não fazem parte, os requisitos ligados aos conteúdos específicos de lições que podem ser alteradas conforme os objetivos de ensino e o tipo de linguagem mudem. O interesse deste trabalho está nos requisitos que destacam as diferenças que se deve considerar para a vantagem de um público SD. As diferenças podem ser sutis às vezes, mas os requisitos para um jogo ou software genérico e os para aplicações SD, de fato, diferem. Por exemplo, normalmente na mecânica de jogos, o jogador geralmente é penalizado por não terminar uma determinada tarefa após um certo número de tentativas ou dentro de um limite de tempo. Dependendo do contexto, o jogador pode até ser punido com mensagens piscando na tela, música rude e repreensão verbal. Entretanto, não é exatamente assim no caso de um contexto SD, já que os especialistas sugerem que deve haver um limite mais elástico para o tempo ou tentativas e que a mecânica deve convencer os jogadores a continuarem tentando para acertarem eventualmente, fornecendo feedback frequente $\mathrm{e}$ parabenizando-os por seu sucesso. 
Os requisitos para g-apps $S D$ visam apoiar de um lado, o "jogador" (aprendiz SD) e do outro, o "supervisor" - terapeuta, professor, instrutor ou pais que possam preparar materiais, guiar e supervisionar as atividades dos jogadores. Uma g-app $S D$ executa em dispositivos móveis e máquinas desktop conectados com a Web e funciona tanto com o propósito de entretenimento (jogos e brincadeiras) quanto com o de estudar lições gamificadas e fazer trabalhos, tais como responder a exercícios, trabalhos de casa e missões. O trabalho pode ser feito sozinho, por um grupo de jogadores ou sob a supervisão de parentes e instrutores. Missões podem ser realizadas online, no mundo real ou em ambos (realidade alternada). Finalizado com sucesso o trabalho, o jogador recebe recompensas e pontos por mérito. Com a g-app $S D$, supervisores preparam lições, checam as atividades, definem missões e monitoram o desempenho do jogador.

Na primeira interação da metodologia, a coleta de dados com atores nas etapas i) e ii) foram feitas de forma simultânea por meio do uso de entrevistas semiestruturadas, resultando em um total de 19 requisitos. Na etapa iii) foram encontrados 18 requisitos a partir dos softwares analisados e mais 82 na etapa iv), a partir da revisão da literatura, totalizando assim 119 requisitos. $\mathrm{Na} \mathrm{v),} \mathrm{os} 119$ requisitos encontrados foram reduzidos para 76 e, então, classificados de acordo com as suas peculiaridades e funcionalidades na etapa vi), em 8 classes, visando organizar e direcionar o projeto de g-apps $S D$ que ofereçam, além do aspecto educacional, entretenimento e diversão para motivar um maior engajamento pelos jogadores. A Tabela 1 apresenta um quadro geral com o número de requisitos elicitados por etapa e classe, enquanto a Tabela 2 apresenta todos os requisitos encontrados ao fim da etapa 2.

Tabela 1: Número de requisitos elicitados por etapa e classe para $g$-apps $S D$

\begin{tabular}{|c|c|c|c|c|c|}
\hline \multirow{2}{*}{ Classe } & \multicolumn{4}{|c|}{$\begin{array}{l}\text { Requisitos elicitados } \\
\text { por etapa }\end{array}$} & \multirow{2}{*}{ Exemplos de requisitos } \\
\hline & $\begin{array}{c}\mathrm{i}+ \\
\mathrm{ii}\end{array}$ & iii & iv & $\mathbf{v}$ & \\
\hline $\begin{array}{l}\text { Navegação \& } \\
\text { Interface }\end{array}$ & 2 & 6 & 29 & 31 & $\begin{array}{l}\text { Aspectos relacionados com a tela, tais como botões (grande, } \\
\text { escuros com letras claras), imagens (preferência por fotografias à } \\
\text { pinturas), cores (devem ser brilhantes) e fontes (Serif). }\end{array}$ \\
\hline $\begin{array}{l}\text { Elementos de } \\
\text { gamificação \& } \\
\text { Motivação }\end{array}$ & 1 & 2 & 21 & 11 & $\begin{array}{l}\text { Jogo de realidade alternada, suporte para avatares e moeda de jogo, } \\
\text { integração com outros jogos online e físicos, sistemas de confiança } \\
\text { e recompense, criação e gerenciamento de incentivos tangíveis e } \\
\text { intangíveis e de quadro de líderes (leaderboard). }\end{array}$ \\
\hline $\begin{array}{l}\text { Mecânicas de } \\
\text { jogos \& } \\
\text { configuração } \\
\text { do sistema }\end{array}$ & 7 & 5 & 7 & 11 & $\begin{array}{l}\text { Repetição, duração e outras regras relativos a atividades, } \\
\text { recompensas, e configuração de usuários e privilégios. }\end{array}$ \\
\hline Atividades & 4 & 4 & 6 & 8 & $\begin{array}{l}\text { Ferramentas de especificação para ajudar especialistas, instrutores } \\
\text { e profissionais a desenvolverem material multimídia (lições, } \\
\text { missões, tarefas) para jogadores e supervisores. }\end{array}$ \\
\hline $\begin{array}{l}\text { Ferramentas e } \\
\text { suporte aos } \\
\text { profissionais }\end{array}$ & 2 & 1 & 5 & 5 & $\begin{array}{l}\text { Funcionalidades para ajudar os supervisores (terapeutas, } \\
\text { instrutores, ...) em gerenciar o processo de aprendizagem com } \\
\text { métricas de performance dos jogadores, customização de tarefas } \\
\text { para jogadores específicos e concessão de recompensas. }\end{array}$ \\
\hline $\begin{array}{l}\text { Feedback \& } \\
\text { ajuda }\end{array}$ & 3 & 0 & 7 & 5 & $\begin{array}{l}\text { Suporte para interações multimídia com os jogadores, alertas e } \\
\text { lembretes de tarefas pendentes, parabenizar os jogadores por } \\
\text { completar tarefas ou partes delas, frequente feedback positivo e } \\
\text { estimulação de recomendações corretivas; respostas para ajudar } \\
\text { jogadores. }\end{array}$ \\
\hline Entradas & 0 & 0 & 2 & 3 & $\begin{array}{l}\text { Diretrizes para o uso do mouse, teclado e telas multi touch para os } \\
\text { jogadores. }\end{array}$ \\
\hline Socialização & 0 & 0 & 2 & 2 & $\begin{array}{l}\text { Requisitos para apoiar as interações dos jogadores com as pessoas } \\
\text { que fazem os profissionais ou com outros jogadores dentro do } \\
\text { aplicativo, como conversar, fazer trabalhos em grupo, trocar } \\
\text { presentes ou comprar produtos usando pontos. }\end{array}$ \\
\hline
\end{tabular}


Tabela 2: Lista de requisitos. Os números de i à iv representam as etapas da coleta de requisitos apresentadas na metodologia

\begin{tabular}{|c|c|c|c|}
\hline Classe & ID & Descrição do requisito & Fonte \\
\hline \multirow{30}{*}{$\begin{array}{l}\text { Navegação e } \\
\text { Interface }\end{array}$} & NI.1 & Usar fontes do tipo italic Serif, principalmente, em títulos e subtópicos. & [iv] \\
\hline & NI.2 & Utilizar fontes com contornos e cores brilhantes. & [iv] \\
\hline & NI.3 & Utilizar palavras grandes com negrito forte. & [iv] \\
\hline & NI.4 & $\begin{array}{c}\text { Usar cores e escalas (tamanhos) diferentes para destacar palavras } \\
\text { importantes em sentenças/frases. }\end{array}$ & [iv] \\
\hline & NI.5 & $\begin{array}{c}\text { Utilizar palavras estilizadas com elementos gráficos destacados (como } \\
\text { estrelas no fundo, setas, elementos coloridos). }\end{array}$ & [iv] \\
\hline & NI.6 & $\begin{array}{l}\text { Não utilizar decorações de fonte que alterem o formato da letra ou que } \\
\text { possuam contornos escurecidos e sombreamento. }\end{array}$ & [iv $]$ \\
\hline & NI.7 & $\begin{array}{c}\text { Utilizar nas telas da aplicação cores de tons escuros como: cores azuladas, } \\
\text { púrpuras e cinzas. }\end{array}$ & $\begin{array}{l}{[\mathrm{iii}]} \\
\text { [iv] }\end{array}$ \\
\hline & NI.8 & $\begin{array}{l}\text { Quando a opção de alto contraste for selecionado, não utilizar somente cores } \\
\text { primárias. }\end{array}$ & $\begin{array}{l}{[\mathrm{iii}]} \\
{[\mathrm{iv}]}\end{array}$ \\
\hline & NI.9 & Não utilizar cores opacas. & [iv] \\
\hline & NI.10 & $\begin{array}{l}\text { Utilizar imagens de objetos, pessoas e animais que sejam familiares aos } \\
\text { jogadores e possam ser facilmente identificados. }\end{array}$ & [iv] \\
\hline & NI.11 & $\begin{array}{c}\text { Utilizar preferencialmente imagens com cores naturais em vez de imagens } \\
\text { coloridas ou manipuladas digitalmente. }\end{array}$ & [iv $]$ \\
\hline & NI.12 & Utilizar imagens de pessoas, principalmente, jovens e bonitas. & [iv] \\
\hline & NI.13 & $\begin{array}{l}\text { Utilizar imagens de ação com pessoas pulando, dançando, gesticulando ou } \\
\text { praticando algum tipo de esporte (ex: jogando futebol). }\end{array}$ & [iv] \\
\hline & NI.14 & Utilizar mais imagens fotográficas do que ilustrações. & [iv] \\
\hline & NI.15 & $\begin{array}{l}\text { Utilizar principalmente imagens de pessoas com a mesma idade ou mais } \\
\text { velhas que as crianças e adolescentes utilizando a aplicação. }\end{array}$ & [iv $]$ \\
\hline & NI.16 & Utilizar ilustrações de estrelas nos botões e no fundo tela. & [iv] \\
\hline & NI.17 & $\begin{array}{c}\text { Utilizar imagens de pessoas, principalmente, com SD em vez de outras } \\
\text { imagens ou ilustrações. }\end{array}$ & [iv $]$ \\
\hline & NI.18 & $\begin{array}{l}\text { Utilizar imagens literais/concretas (ex: garoto jogando bola, crianças } \\
\text { brincando, o rato comendo queijo, etc) são melhores que abstratas (ex: } \\
\text { objetos com formato e cores fora da realidade); }\end{array}$ & [iv] \\
\hline & NI.19 & $\begin{array}{l}\text { Utilizar animações coloridas que combinem cores brilhantes com } \\
\text { movimento. }\end{array}$ & [iv $]$ \\
\hline & NI.20 & $\begin{array}{c}\text { Permitir que as crianças/jovens possam personalizar algumas animações } \\
\text { adicionando objetos e nomes. (ex: adicionar uma estrela ou o nome em uma } \\
\text { animação de uma bola saltando). }\end{array}$ & [iv] \\
\hline & NI.21 & $\begin{array}{l}\text { Evitar uso de animações com movimentos visuais complexos. Pessoas com } \\
\text { SD são capazes de realizarem discriminação perceptiva básica, mas } \\
\text { apresentam dificuldades na percepção de sugestões de movimentos visuais } \\
\text { complexos. }\end{array}$ & [iv] \\
\hline & NI.22 & Utilizar sons de desenho animado (divertidos e exagerados). & [iv] \\
\hline & NI.23 & $\begin{array}{c}\text { Usar canções infantis e músicas populares para estimular as crianças (talvez } \\
\text { o uso da música deva ser personalizada para cada jogador). }\end{array}$ & $\begin{array}{l}{[\mathrm{i}+\mathrm{ii}]} \\
{[\mathrm{iv}]}\end{array}$ \\
\hline & NI.24 & $\begin{array}{l}\text { Utilizar Botões clicáveis grandes, claros, com formatos bem definidos e bem } \\
\text { rotulados. }\end{array}$ & [iv $]$ \\
\hline & NI.25 & $\begin{array}{l}\text { Os botões devem ter o fundo de cor escura e o texto de cor clara (alto } \\
\text { contraste). }\end{array}$ & [iv] \\
\hline & NI.26 & $\begin{array}{c}\text { Utilizar botões em locais fixos e de fácil visualização. Evitar usar botões } \\
\text { flutuantes (botões ocultos por um menu). }\end{array}$ & [iv $]$ \\
\hline & NI.27 & $\begin{array}{l}\text { Utilizar setas apontando para o botão quando for necessário chamar atenção } \\
\text { dos jogadores para eles. }\end{array}$ & [iv $]$ \\
\hline & NI.28 & Texto e voz (narrações e explicações) devem ser curtos e simples. & $\begin{array}{l}{[\mathrm{iii}]} \\
{[\mathrm{i}+\mathrm{ii}]}\end{array}$ \\
\hline & NI.29 & $\begin{array}{l}\text { Evitar o uso de frases condicionais (ex: "primeiro, clique nesse botão para } \\
\text { depois clicar naquele outro). É interessante dividir as instruções em etapas. }\end{array}$ & [iii] \\
\hline & NI.30 & Evitar o uso de menus suspensos, pois são difíceis para usuários com SD. & [iv] \\
\hline
\end{tabular}




\begin{tabular}{|c|c|c|c|}
\hline & NI.31 & $\begin{array}{l}\text { Evitar o excesso de informações na tela. Crianças com Déficit de atenção } \\
\text { são propensas a perderem o foco facilmente, por isso telas com muitas } \\
\text { informações podem dificultar que elas se encontrem dentro da aplicação. } \\
\text { Elas podem esquecer o que estavam procurando e não conseguir mais } \\
\text { identificar qual era o objetivo anterior. }\end{array}$ & [iv] \\
\hline \multirow{5}{*}{$\begin{array}{l}\text { Feedback e } \\
\text { Ajuda }\end{array}$} & FA.1 & $\begin{array}{c}\text { Utilizar efeitos sonoros, visuais e de vibração como forma de dar um } \\
\text { feedback instantâneo imediato ao jogador. Ex: utilizar efeitos sonoros que } \\
\text { indiquem quando o jogador faz algo certo ou errado em algum jogo ou } \\
\text { quando ele ganha uma recompensa. }\end{array}$ & $\begin{array}{l}{[\mathrm{i}+\mathrm{ii}]} \\
{[\mathrm{iv}]}\end{array}$ \\
\hline & FA.2 & $\begin{array}{c}\text { Utilizar avisos/lembretes para lembrar aos jogadores sobre as atividades que } \\
\text { eles têm que fazer. }\end{array}$ & [iv] \\
\hline & FA.3 & $\begin{array}{l}\text { Caso a criança cometa algum erro durante a realização de uma atividade, o } \\
\text { sistema deve dar um feedback imediato para ela demonstrando o erro e, em } \\
\text { alguns casos, o que fazer para resolvê-lo. Ex: efeitos sonoros, explicações } \\
\text { gravadas, etc. }\end{array}$ & [iv] \\
\hline & FA.4 & $\begin{array}{c}\text { Dar recompensas e elogiar os jogadores sempre que eles terminarem alguma } \\
\text { atividade. }\end{array}$ & $\begin{array}{l}{[\mathrm{i}+\mathrm{ii}]} \\
{[\mathrm{iv}]}\end{array}$ \\
\hline & FA.5 & $\begin{array}{l}\text { Evitar demonstrar reações negativas quando o estudante comete erros (ex: } \\
\text { utilizar a mensagem "você perdeu" caso o jogador não consiga terminar a } \\
\text { atividade). }\end{array}$ & $\begin{array}{l}{[\mathrm{i}+\mathrm{ii}]} \\
{[\mathrm{iv}]}\end{array}$ \\
\hline \multirow{3}{*}{ Entradas } & IN.1 & $\begin{array}{l}\text { Evitar o uso do teclado, pois crianças com SD têm dificuldades de encontrar } \\
\text { as letras nele. }\end{array}$ & [iv] \\
\hline & IN.2 & $\begin{array}{l}\text { Evitar o uso do mouse. As crianças com SD apresentam dificuldades de } \\
\text { interagir com o mouse e a tela do computador ao mesmo tempo. }\end{array}$ & [iv] \\
\hline & IN.3 & Utilizar telas multi touch. & [iv] \\
\hline \multirow[t]{2}{*}{ Socialização } & S.1 & $\begin{array}{c}\text { Criar mecanismos que permitam as crianças interagir entre si dentro da } \\
\text { aplicação, pode ajudar a resolver o problema de isolamento e a encontrar } \\
\text { amigos que possuam a mesma idade. (Talvez, a troca e envios de presentes } \\
\text { pela aplicação possam ajudar nessa interação). }\end{array}$ & [iv] \\
\hline & S.2 & $\begin{array}{l}\text { Usar personagens ou personalidades (atores, pessoas famosas da televisão } \\
\text { ou da mídia, etc) para guiarem o aprendizado. }\end{array}$ & [iv] \\
\hline \multirow{8}{*}{ Atividades } & A. 1 & $\begin{array}{l}\text { Criar atividades que permitam que as crianças sejam capazes de interagir } \\
\text { com os brinquedos que estão familiarizadas por meio do uso da câmera. }\end{array}$ & [iv] \\
\hline & A. 2 & $\begin{array}{c}\text { Criar atividades de revisão ao fim de cada conteúdo (Módulo ou conjunto de } \\
\text { atividades que possuam as mesmas características). }\end{array}$ & [iv] \\
\hline & A. 3 & $\begin{array}{l}\text { Criar atividades em que os jogadores devem escrever letras na tela } \\
\text { utilizando o dedo ou uma caneta especifica para telas multi touch. }\end{array}$ & $\begin{array}{l}{[\mathrm{i}+\mathrm{ii}]} \\
{[\mathrm{iv}]}\end{array}$ \\
\hline & A. 4 & $\begin{array}{l}\text { Criar atividades que permitam os pais interagirem com as crianças/jovens } \\
\text { (ex: jogos que envolvam os pais e filhos). }\end{array}$ & {$[\mathrm{iv}]$} \\
\hline & A. 5 & $\begin{array}{l}\text { Criar atividades que façam os jogadores imitarem o comportamento/ações } \\
\text { dos pais, terapeutas e personagens dentro da aplicação. }\end{array}$ & [iv] \\
\hline & A. 6 & Uso de jogos do gênero puzzle (forca, quebra-cabeças, etc) e memorização. & $\begin{array}{l}{[\mathrm{i}+\mathrm{ii}]} \\
{[\mathrm{iv}]}\end{array}$ \\
\hline & A. 7 & Criar atividades musicais para os jogadores (ex: jogos de karaokê). & $\begin{array}{l}{[\mathrm{i}+\mathrm{ii}]} \\
{[\mathrm{iv}]}\end{array}$ \\
\hline & A. 8 & $\begin{array}{l}\text { Criar um sistema de missões em que os jogadores devem tirar fotos de } \\
\text { locais, pessoas e objetos para ganharem recompensas. Esse tipo de atividade } \\
\text { é bom para estimular a interação com os pais e cuidadores. }\end{array}$ & {$[\mathrm{i}+\mathrm{ii}]$} \\
\hline \multirow{5}{*}{$\begin{array}{l}\text { Elementos de } \\
\text { gamificação e } \\
\text { de motivação }\end{array}$} & EG.1 & $\begin{array}{l}\text { Utilizar recompensas tangíveis (exemplo: ingressos para o cinema, doces, } \\
\text { chocolate, dinheiro, etc). }\end{array}$ & [iv] \\
\hline & EG.2 & $\begin{array}{l}\text { Utilizar recompensas intangíveis. Exemplo: elogios e prêmios dentro da } \\
\text { aplicação. }\end{array}$ & [iv] \\
\hline & EG.3 & $\begin{array}{l}\text { Utilização de pontos: sempre que o jogador terminar uma atividade ele deve } \\
\text { receber pontos de acordo com o seu desempenho. }\end{array}$ & [iv] \\
\hline & EG.4 & $\begin{array}{l}\text { Utilização de insígnias/conquistas. Sempre que o jogador atingir uma } \\
\text { quantidade de pontos ou realizar algum tipo específico de atividade ou } \\
\text { comportamento, ele receberá uma insígnia ou um conquista (um tipo de } \\
\text { troféu) como recompensa. }\end{array}$ & [iv] \\
\hline & EG.5 & $\begin{array}{l}\text { Criar de um sistema de progressão no qual o jogador possui um nível e } \\
\text { conforme for fazendo as atividades e ganhando pontos de experiência, o }\end{array}$ & [iv $]$ \\
\hline
\end{tabular}




\begin{tabular}{|c|c|c|c|}
\hline & & $\begin{array}{c}\text { nível do jogador vai aumentando e, junto com isso, a dificuldade das } \\
\text { atividades. }\end{array}$ & \\
\hline & EG.6 & $\begin{array}{l}\text { Criar um quadro de líderes (leaderboards), onde será ranqueado o } \\
\text { desempenho de todos os jogadores. Tem como principal função incentivar o } \\
\text { clima de competição amistosa entre os jogadores. }\end{array}$ & [iv] \\
\hline & EG.7 & $\begin{array}{l}\text { Criar um sistema de troca de presentes entre os jogadores. Abordagem para } \\
\text { motivar a interação amistosa e colaborativa. }\end{array}$ & [iv] \\
\hline & EG.8 & $\begin{array}{c}\text { Permitir que os jogadores possam criar e customizar avatares que os } \\
\text { representem dentro da aplicação. }\end{array}$ & [iv] \\
\hline & EG.9 & $\begin{array}{l}\text { Criar um sistema monetário que permita que os jogadores recebam dinheiro } \\
\text { fictício dentro da aplicação e possam comprar itens para customizar seus } \\
\text { avatares. }\end{array}$ & [iv] \\
\hline & $\begin{array}{c}\text { EG.1 } \\
0\end{array}$ & $\begin{array}{l}\text { Criar um sistema de desafio em que os jogadores terão que utilizar todos os } \\
\text { conhecimentos adquiridos em atividades anteriores para resolvê-los. Este } \\
\text { tipo de atividade dão mais recompensas ao jogador. }\end{array}$ & [iv] \\
\hline & $\begin{array}{c}\text { EG.1 } \\
1\end{array}$ & $\begin{array}{l}\text { Criar um enredo/tema para estimular o pensamento abstrato nos jogadores e } \\
\text { contribuir para imersão dos jogadores na aplicação. }\end{array}$ & $\begin{array}{c}{[\mathrm{i}+\mathrm{ii}]} \\
{[\mathrm{iv}]}\end{array}$ \\
\hline \multirow{11}{*}{$\begin{array}{l}\text { Mecânicas e } \\
\text { configurações } \\
\text { do sistemas }\end{array}$} & MC.1 & $\begin{array}{l}\text { Criar uma loja dentro do próprio aplicativo que possibilite aos jogadores } \\
\text { gastarem o dinheiro recebido nas missões/atividades. }\end{array}$ & {$[\mathrm{i}+\mathrm{ii}]$} \\
\hline & MC. 2 & $\begin{array}{l}\text { As recompensas aos jogadores não devem ser restritas apenas à realização } \\
\text { de atividades como também a frequência com o que o usuário utiliza o } \\
\text { aplicativo ou faz atividades fora que não envolvem o aplicativo. }\end{array}$ & {$[\mathrm{i}+\mathrm{ii}]$} \\
\hline & MC.3 & $\begin{array}{l}\text { A avaliação do terapeuta deve servir como um mediador para o valor } \\
\text { recompensa. }\end{array}$ & {$[\mathrm{i}+\mathrm{ii}]$} \\
\hline & MC.4 & $\begin{array}{l}\text { Criar perfis diferentes para cada tipo de usuário, dando acesso a diferentes } \\
\text { funcionalidades dentro do aplicativo. Ex: perfil do professor, perfil do aluno } \\
\text { e perfil dos pais. }\end{array}$ & {$[\mathrm{i}+\mathrm{ii}]$} \\
\hline & MC. 5 & $\begin{array}{l}\text { Permitir que os jogadores possam errar quantas vezes forem necessárias até } \\
\text { conseguir entender o que devem fazer na atividade. }\end{array}$ & $\begin{array}{c}{[\mathrm{i}+\mathrm{ii}]} \\
{[\mathrm{iv}]} \\
\end{array}$ \\
\hline & MC.6 & $\begin{array}{l}\text { As atividades não devem possuir limite de tempo para serem resolvidas e } \\
\text { podem ser repetidas/refeitas quantas vezes forem necessárias. }\end{array}$ & {$[\mathrm{iv}]$} \\
\hline & MC.7 & $\begin{array}{l}\text { As atividades propostas no jogo devem acompanhar a curva de aprendizado } \\
\text { e a idade do jogador. }\end{array}$ & [iv] \\
\hline & MC.8 & $\begin{array}{l}\text { As instruções de como realizar as atividades ou de ajuda, além de serem } \\
\text { apresentadas de forma visual (texto e imagens), também devem ser } \\
\text { apresentadas por meio de áudios explicativos. }\end{array}$ & $\begin{array}{l}{[\mathrm{i}+\mathrm{ii}]} \\
{[\mathrm{iii}]} \\
{[\mathrm{iv}]}\end{array}$ \\
\hline & MC.9 & $\begin{array}{c}\text { Permitir que as crianças ao clicar em letras do alfabeto ou palavras } \\
\text { destacadas possam escutar o som dos grafemas e exibir animações } \\
\text { demonstrando como os traços necessários para formar a letra devem ser } \\
\text { feito. }\end{array}$ & $\begin{array}{l}{[\mathrm{i}+\mathrm{ii}]} \\
{[\mathrm{iv}]}\end{array}$ \\
\hline & $\begin{array}{c}\text { MC.1 } \\
0\end{array}$ & $\begin{array}{l}\text { Permitir que jogadores sempre tenham acesso às instruções de como fazer as } \\
\text { atividades sempre que quiserem. }\end{array}$ & [iv] \\
\hline & $\begin{array}{c}\text { MC.1 } \\
1\end{array}$ & $\begin{array}{c}\text { Fazer uso dos estímulos visuais, sonoros e de tato de forma ordenada para } \\
\text { evitar que haja sobreposição de estímulos e atrapalhe ou confunda o } \\
\text { processo cognitivo dos jogadores; }\end{array}$ & [iv] \\
\hline \multirow{5}{*}{$\begin{array}{l}\text { Ferramentas e } \\
\text { suporte para o } \\
\quad \text { terapeuta }\end{array}$} & FS.1 & $\begin{array}{l}\text { Disponibilizar para o terapeuta métricas de avaliação de desempenho de } \\
\text { cada jogador ao realizar uma determinada atividade (ex: número de } \\
\text { acertos/erros e tempo); }\end{array}$ & $\begin{array}{c}{[\mathrm{i}+\mathrm{ii}]} \\
{[\mathrm{iv}]}\end{array}$ \\
\hline & FS.2 & $\begin{array}{c}\text { Permitir que os terapeutas possam passar atividades únicas para cada } \\
\text { criança, ou seja, permitir que o professor também possa definir atividades } \\
\text { específicas para cada jogador, já que diferentes jogadores podem precisar } \\
\text { estimular diferentes habilidades. }\end{array}$ & [iv] \\
\hline & FS.3 & $\begin{array}{l}\text { Permitir que os terapeutas criem, customizem e especifiquem suas próprias } \\
\text { atividades. }\end{array}$ & [iv] \\
\hline & FS.4 & $\begin{array}{l}\text { Permitir que o terapeuta possa avaliar de forma rápida quase instantânea as } \\
\text { atividades dos alunos. }\end{array}$ & [iv] \\
\hline & FS.5 & $\begin{array}{l}\text { Permitir que os terapeutas e pais atribuam recompensas aos jogadores } \\
\text { quando acharem necessário (ex: os jogadores receberem recompensas por } \\
\text { bom comportamento). }\end{array}$ & {$[\mathrm{i}+\mathrm{ii}]$} \\
\hline
\end{tabular}


Iterações adicionais da metodologia consolidarão o conjunto de requisitos para g-apps $S D$. Um conjunto consolidado servirá como uma referência para o design de aplicações de software gamificadas para alfabetizar em língua portuguesa crianças com SD. Desenvolvedores terão, assim, uma base para definirem versões de software em termos de quais requisitos incluir em uma nova versão de um jogo, dada a importância em temos de utilidade para jogadores com SD e profissionais. É válido observar que o conjunto de classes e seus requisitos na Tabela 1 e 2 irão mudar com iterações adicionais da metodologia ágil da Seção 3, uma vez que a elicitação a partir das diversas fontes continua e experimentos de validação são realizados.

\section{Validação do conjunto inicial de classes e requisitos}

Concluída a classificação dos requisitos, foram realizadas entrevistas adicionais e aplicados questionários de opinião junto aos atores nas etapas vii) e viii). As perguntas nos questionários eram de formato aberto e destinadas a validar a pertinência das classes e seus requisitos no conjunto inicial da Tabela 1 - resultante das etapas de i) a vi); a ordenar as classes de requisitos segundo a importância relativa para a implementação de g-apps $S D$; e, a responder à Questão de Pesquisa (QP). Como esta pesquisa sobre g-apps $S D$ se desenvolve em cooperação entre investigadores do Brasil e da Austrália, os experimentos de validação para responder à QP aconteceram nestes dois países.

No Brasil, participaram 9 validadores, sendo cinco profissionais atuantes em SD (1 especialista em Letras Vernáculas; 2 em Psicologia; 1 em Fonoaudiologia; e, 1 em Pedagogia) e quatro pais de jovens com SD (2 odontólogos; 1 com especialização em Letras Vernáculas; e 1 em Serviço Social). Na Austrália, foram dois especialistas em Design de jogos - um deles parente de uma pessoa com SD. O tempo médio de experiência ou de contato com SD dos 11 validadores é de 9,6 anos. A pequena quantidade de validadores e de potenciais usuários com SD indicam que os resultados do experimento de validação devem ser vistos como preliminares.

A coleta de dados para validação ocorreu em duas fases. Na primeira fase, foi feita a validação das classes, apresentando-se aos validadores, um questionário onde, em resumo, se pediam: a) o descarte de classes que julgassem desnecessárias; b) o acréscimo de novas classes que estivessem em falta; e, c) a resposta à QP, ou seja, se eles acreditavam que g-apps $S D$ com as classes de requisitos propostos seriam úteis para a alfabetização de crianças com SD e facilitariam o trabalho didático dos profissionais. Um outro questionário solicitava a cada validador que ordenasse as classes de requisitos (inclusive, as classes que porventura tivesse acrescentado) segundo a importância para a construção de g-apps $S D$. Essa ordenação contribuirá para o projeto e implementação de g-apps $S D$, identificando requisitos que devem receber mais atenção e prioridade durante o desenvolvimento de protótipo(s) para testes com os usuários.

$\mathrm{Na}$ segunda fase, participantes do Brasil validaram cada um dos requisitos contidos nas classes apresentadas na Tabela 1. As alternativas de validação eram: aceitar o requisito como especificado, sem restrição; questionar o requisito como apresentado, sugerindo ajustes na sua especificação; ou, lançar dúvida sobre a utilidade do requisito, sugerindo sua remoção do conjunto. Os respondentes podiam também, acrescentar novos requisitos ao conjunto, caso achassem necessário. Além disso, também foi perguntado se, assim como com as classes, os respondentes acreditavam na utilidade dos requisitos para a alfabetização de crianças com SD e para o trabalho didático dos profissionais.

\subsection{Análise dos resultados}

Os resultados da primeira fase da coleta de dados indicaram que: a) todos os entrevistados acreditavam ser desnecessário adicionar ou descartar classes às da tabela 1; e, b) as classes na 
Tabela 1 são úteis para a alfabetização de crianças com SD e facilitarão o trabalho didático dos profissionais. Obteve-se, assim, uma resposta afirmativa à QP quanto às classes.

A Figura 1 mostra a média de ordenação $\left(1^{\circ}\right.$ ao $8^{\circ}$ lugar - respectivamente, da classe menos prioritária para a mais) de cada classe e o respectivo intervalo de variação da média com $90 \%$ de confiança e 10 graus de liberdade. Como se observa, as respostas têm intervalos de confiança sobrepostos e por isso, não é ainda possível identificar com certeza, prioridades relativas entre a maioria das classes. Entretanto, é possível afirmar com $90 \%$ de confiança que a classe de Navegação \& Interface apresenta prioridade significativamente maior - ou seja, em primeiro lugar - que todas as demais, exceto pela classe Entradas, cujo intervalo [5.09; 7,45] se sobrepõe. Também é possível afirmar com $90 \%$ de confiança que a classe Entradas possui prioridade maior que a classe de Ferramentas \& suporte aos profissionais. Além disso, ao observamos a média amostral apresentada na figura, notam-se indícios de que, possivelmente, a classe Entradas também possui uma alta prioridade na opinião dos entrevistados, enquanto que as classes de Gamificação e de Ferramentas \& Suporte aparentam ter papéis mais secundários.

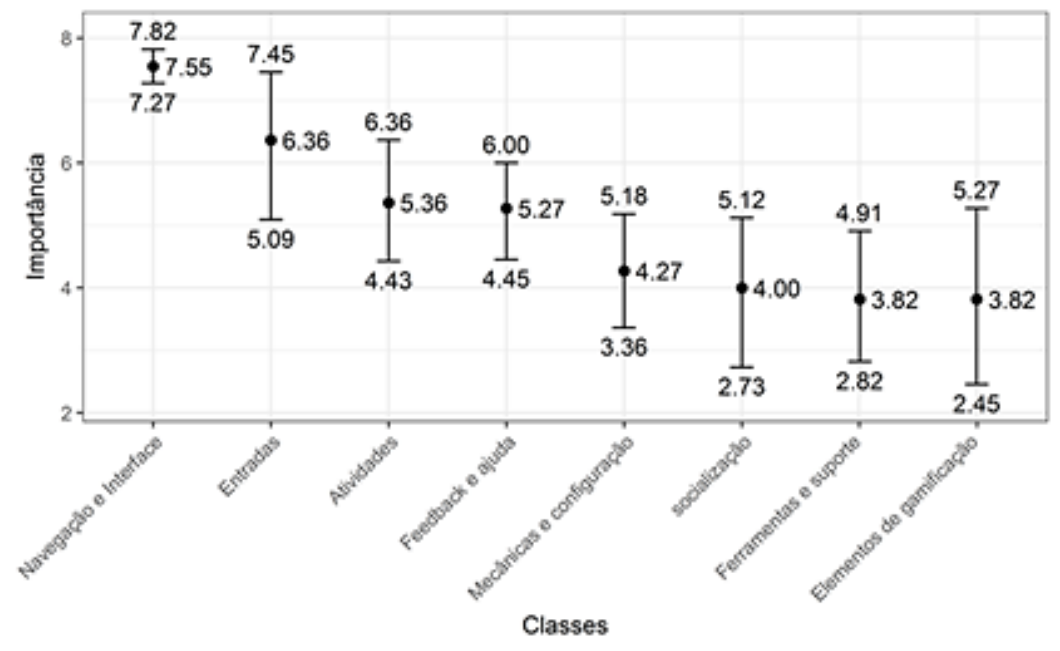

Figura 2: Priorização geral dos requisitos de acordo com a importância (Média centrada no intervalo)

Uma possível razão para a classe "Elementos de Gamificação" tenha fícado em último na classificação de importância é que o grupo validador não seja constituído de indivíduos com SD. Os membros desse grupo, sendo designers, profissionais atuantes em SD e parentes de pessoas com SD, podem ter valorizado o conteúdo e as instruções pedagógicas mais do que o entretenimento. $\mathrm{Na}$ verdade, as figuras 3, 4 e 5 apresentam a priorização realizada por esses representantes do grupo e é possível observar que em nenhum dos gráficos a classe "Elementos de gamificação" apresenta uma classificação maior que o quarto lugar. De fato, esta classe exibe o maior intervalo com $90 \%$ de confiança em todas as priorizações, tornando-se, assim, a classe cuja importância na classificação foi a que gerou maior dúvida entre os validadores. 


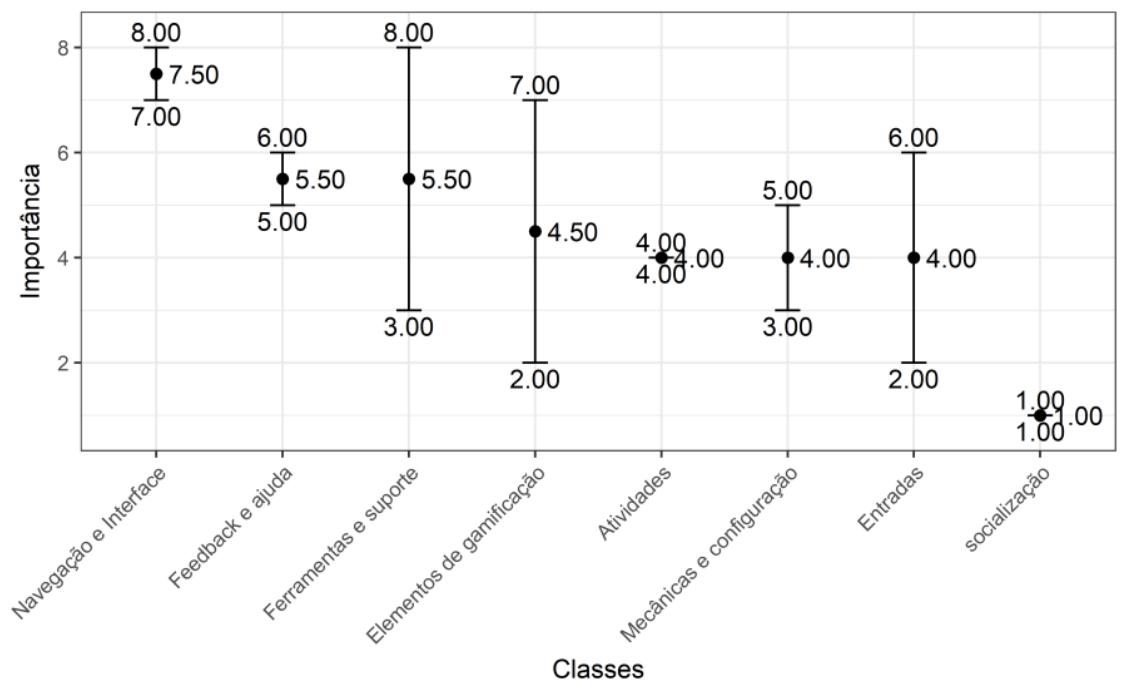

Figura 3: Priorização pelos designers.

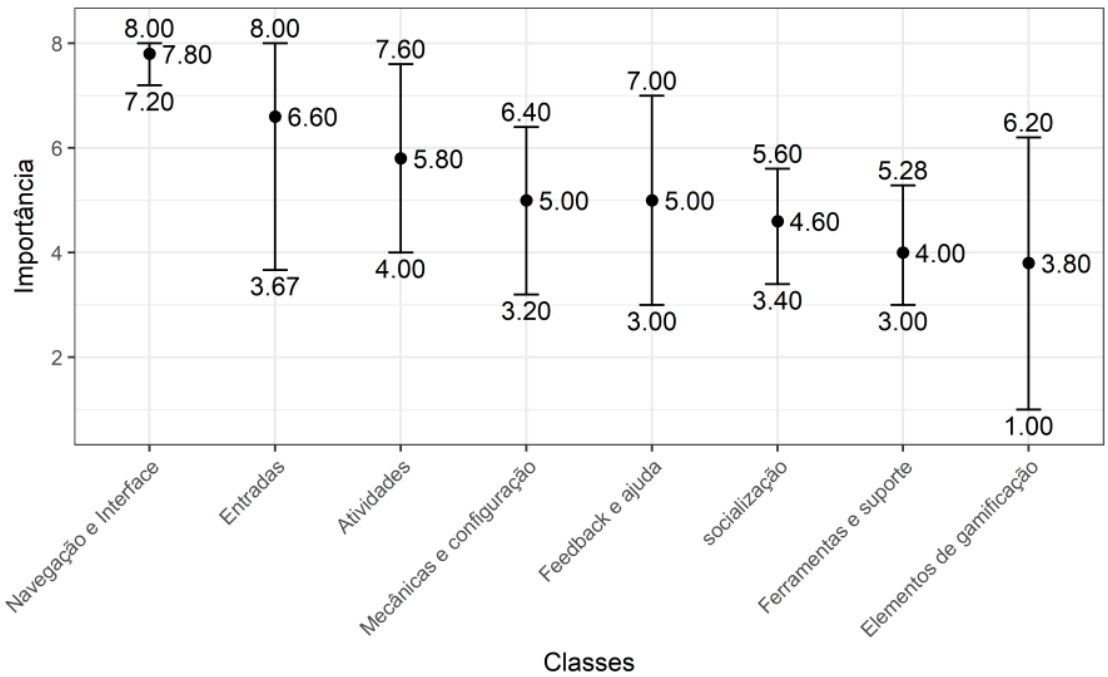

Figura 4: Priorização pelos profissionais

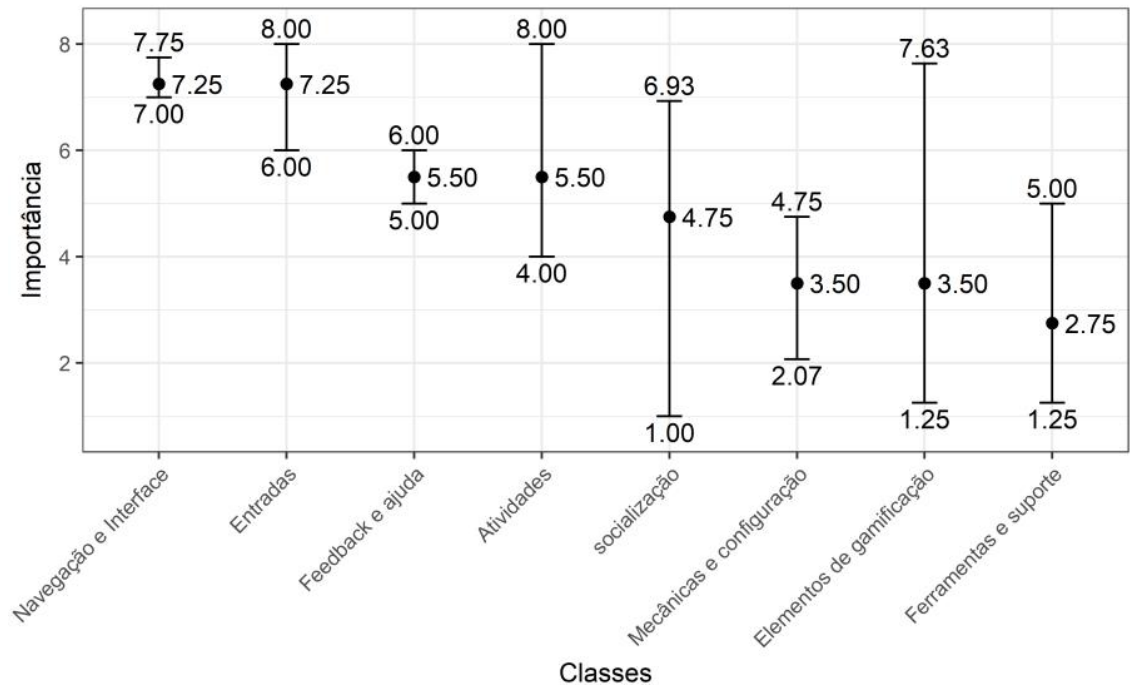

Figura 5: Priorização pelos pais. (Média e intervalo de confiança de 90\%)

As variações nos rankings devido às preferências dos validadores podem ser enfatizadas por meio do gráfico de Análise de Componentes Principais (PCA) na Figura 6: a maioria dos parentes 
são agrupados na direção oposta do vetor que representa a classe "Elementos de Gamificação", demonstrando que, pelo menos durante este primeiro experimento de validação, os parentes acreditam que as outras classes de requisitos - como "Atividades" e "Entradas" - devem ter maior prioridade do que a classe vinculada aos elementos de diversão e motivação. A opinião de especialistas parece mais variada, indo de desde profissionais que acreditam que a Gamificação deve ser classificada com uma maior importância (especialistas em vermelho, à esquerda na Fig. 6) para aqueles que acreditam que ela deve ter uma menor importância (especialistas em verde, à direita na Fig. 6). Um outro ponto importante nesta figura que também deve ser observado, é que devido a classe "Navegação e interface" ter tido prioridades parecidas de acordo a opinião dos entrevistados ela teve pouca influência no posicionamento deles no gráfico.

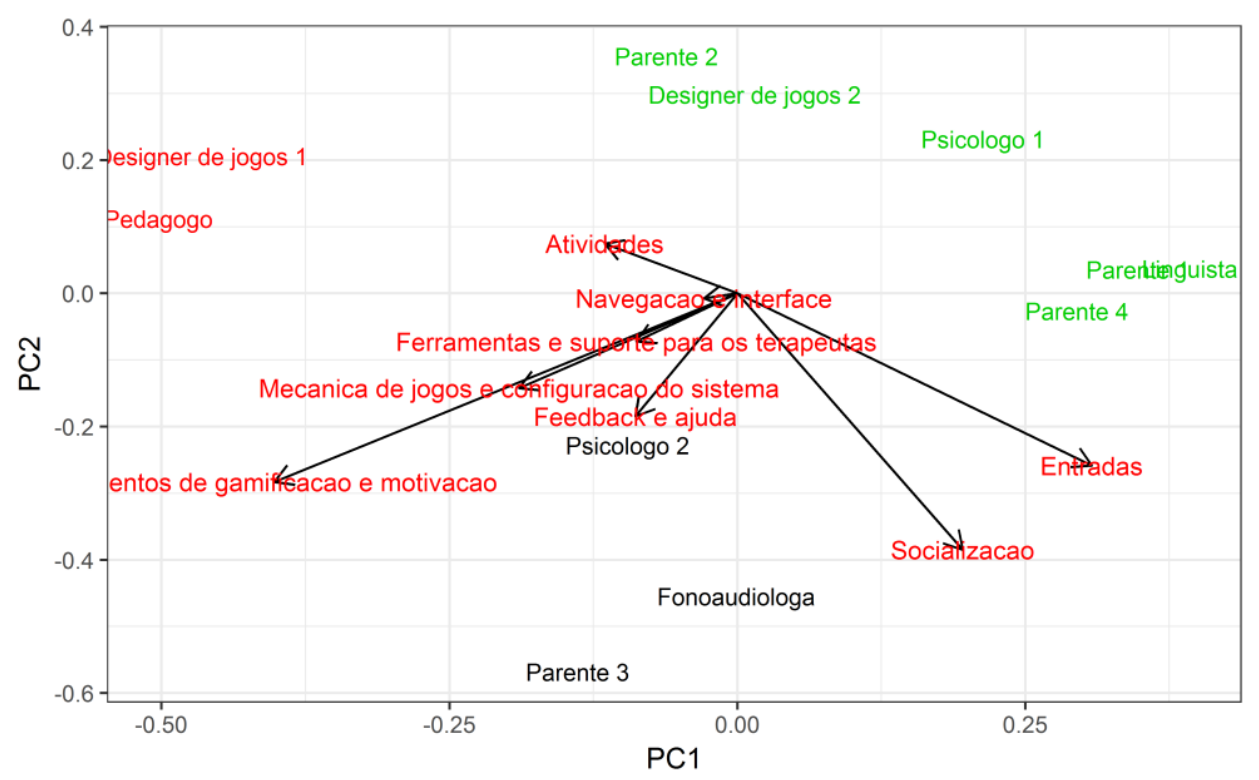

Figura 6: Comportamento dos g-apps validadores na priorização das classes

$\mathrm{Na}$ segunda fase da coleta de dados, todos os entrevistados deram resposta afirmativa à QP, só que agora no que se refere aos requisitos. No entanto, dos 76 requisitos elicitados, 39 (51,3\% do total) foram aceitos como apresentados; 26 receberam de 1 a 3 sugestões a favor da remoção da lista; e outros 11 tiveram de 4 a 8 sugestões também a favor da remoção. Desses 37 requisitos $(26+11)$ que tiveram recomendações a favor da remoção, 16 receberam sugestões para que ajustes semânticos fossem realizados em suas descrições para torna-los mais adequados à criação g-apps $S D$ (p.ex., foi sugerido que "número ilimitado de repetições de tarefas" mudasse para "número configurável de repetições"). Na tabela 3 essas sugestões são apresentadas com mais detalhes. Nela, o índice "recomendações" representa a quantidade de sugestões a favor da remoção do requisito da lista e pode-se observar que 6 dos requisitos presentes nesta tabela fazem parte dos 11 que receberam entre 4 a 8 recomendações para a remoção, apresentando sinais de que possivelmente, mesmo com tais taxas de reprovação nesta fase preliminar do estudo, esses requisitos ainda possam ser reaproveitados a partir dessas sugestões em novos ciclos da metodologia.

Tabela 3: Requisitos que receberam sugestões para alteração semântica

\begin{tabular}{|c|c|c|c|}
\hline ID & Descrição antiga & Sugestão para nova descrição & $\begin{array}{c}\text { Recomenda } \\
\text { ções }\end{array}$ \\
\hline $\begin{array}{c}\text { NI. } \\
1\end{array}$ & $\begin{array}{c}\text { Usar fontes do tipo italic Serif, principalmente, } \\
\text { em títulos e subtópicos. }\end{array}$ & $\begin{array}{c}\text { Utilizar letras em caixa alta com fontes } \\
\text { do tipo Arial ou Times New Roman }\end{array}$ & 7 \\
\hline $\begin{array}{c}\text { NI. } \\
2\end{array}$ & Utilizar fontes com contornos e cores brilhantes & $\begin{array}{c}\text { Utilizar fontes com contornos e cores } \\
\text { brilhantes apenas quando for } \\
\text { necessário destacar palavras na tela }\end{array}$ & 1 \\
\hline
\end{tabular}




\begin{tabular}{|c|c|c|c|}
\hline $\begin{array}{c}\text { NI. } \\
3\end{array}$ & Utilizar palavras grandes com negrito forte & $\begin{array}{c}\text { Utilizar palavras normais (tamanho), } \\
\text { colocando em negrito as que tiverem } \\
\text { que ser destacadas. }\end{array}$ & 1 \\
\hline $\begin{array}{c}\text { NI. } \\
11\end{array}$ & $\begin{array}{c}\text { Utilizar preferencialmente imagens com cores } \\
\text { naturais em vez de imagens coloridas ou } \\
\text { manipuladas digitalmente }\end{array}$ & $\begin{array}{c}\text { Equilibrar o uso entre as imagens com } \\
\text { cores naturais e as coloridas ou } \\
\text { manipuladas digitalmente }\end{array}$ & 3 \\
\hline $\begin{array}{c}\text { NI. } \\
16\end{array}$ & $\begin{array}{l}\text { Utilizar ilustrações de estrelas nos botões e no } \\
\text { fundo da tela. }\end{array}$ & $\begin{array}{l}\text { Utilizar qualquer tipo de figura } \\
\text { (corações, flores, nuvens, etc) no fundo } \\
\text { da tela e nos botões. }\end{array}$ & 6 \\
\hline $\begin{array}{l}\text { NI. } \\
17\end{array}$ & $\begin{array}{c}\text { Utilizar imagens de pessoas, principalmente, } \\
\text { com SD em vez de outras imagens ou } \\
\text { ilustrações. }\end{array}$ & $\begin{array}{l}\text { Utilizar imagens de todas as pessoas } \\
\text { em igual proporção }\end{array}$ & 7 \\
\hline $\begin{array}{l}\text { NI. } \\
21\end{array}$ & $\begin{array}{l}\text { Evitar uso de animações com movimentos } \\
\text { visuais complexos. Pessoas com SD são capazes } \\
\text { de realizarem discriminação perceptiva básica, } \\
\text { mas apresentam dificuldades na percepção de } \\
\text { sugestões de movimentos visuais complexos }\end{array}$ & $\begin{array}{l}\text { O uso de animações complexas deve } \\
\text { ser feito gradualmente conforme a } \\
\text { criança for avançando de nível; }\end{array}$ & 2 \\
\hline $\begin{array}{c}\text { FA. } \\
3\end{array}$ & $\begin{array}{l}\text { Caso a criança cometa algum erro durante a } \\
\text { realização de uma atividade, o sistema deve dar } \\
\text { um feedback imediato para ela demonstrando o } \\
\text { erro e, em alguns casos, o que fazer para } \\
\text { resolvê-lo. Ex: efeitos sonoros, explicações } \\
\text { gravadas, etc. }\end{array}$ & $\begin{array}{c}\text { Caso a criança cometa algum erro } \\
\text { durante a realização de uma atividade, } \\
\text { o sistema deve esperar a reflexão da } \\
\text { criança antes de dar a resposta, } \\
\text { demonstrando aos poucos qual foi o } \\
\text { erro dela e a guiando. }\end{array}$ & 1 \\
\hline S.2 & $\begin{array}{l}\text { Usar personagens ou personalidades (atores, } \\
\text { pessoas famosas da televisão ou da mídia, etc) } \\
\text { para guiarem o aprendizado. }\end{array}$ & $\begin{array}{l}\text { Usar guias personalizados para } \\
\text { guiarem o jogador (permitir que o } \\
\text { jogador crie o próprio guia). }\end{array}$ & 3 \\
\hline $\begin{array}{c}\mathrm{IN} . \\
1\end{array}$ & $\begin{array}{l}\text { Evitar o uso do teclado, pois crianças com SD } \\
\text { têm dificuldades de encontrar as letras nele. }\end{array}$ & $\begin{array}{l}\text { Evitar o uso do teclado somente com as } \\
\text { crianças pequenas }\end{array}$ & 6 \\
\hline $\begin{array}{c}\mathrm{IN} . \\
2\end{array}$ & $\begin{array}{l}\text { Evitar o uso do mouse. As crianças com SD } \\
\text { apresentam dificuldades de interagir com o } \\
\text { mouse e a tela do computador ao mesmo tempo; }\end{array}$ & $\begin{array}{l}\text { Evitar o uso do mouse somente com } \\
\text { crianças pequenas }\end{array}$ & 6 \\
\hline $\begin{array}{c}\mathrm{MC} \\
.3\end{array}$ & $\begin{array}{l}\text { A avaliação do terapeuta deve servir como um } \\
\text { mediador para o valor da recompensa; }\end{array}$ & $\begin{array}{l}\text { Permitir que a avaliação dos pais e } \\
\text { terapeutas sirva como mediador para o } \\
\text { valor da recompensa nas atividades }\end{array}$ & 1 \\
\hline $\begin{array}{c}\mathrm{MC} \\
.5\end{array}$ & $\begin{array}{c}\text { Permitir que os jogadores possam errar quantas } \\
\text { vezes forem necessárias até conseguir entender } \\
\text { o que devem fazer na atividade; }\end{array}$ & $\begin{array}{c}\text { Permitir que o número de vezes que os } \\
\text { jogadores possam errar seja } \\
\text { configurável de acordo à atividade }\end{array}$ & 2 \\
\hline $\begin{array}{l}\mathrm{MC} \\
.6\end{array}$ & $\begin{array}{l}\text { As atividades não devem possuir limite de } \\
\text { tempo para serem resolvidas e podem ser } \\
\text { repetidas/refeitas quantas vezes forem } \\
\text { necessárias; }\end{array}$ & $\begin{array}{l}\text { As atividades devem possuir um tempo } \\
\text { limite e podem ser repetidas quantas } \\
\text { vezes forem necessárias }\end{array}$ & 3 \\
\hline $\begin{array}{c}\text { EG. } \\
1\end{array}$ & $\begin{array}{c}\text { Utilizar recompensas tangíveis (exemplo: } \\
\text { ingressos para o cinema, doces, chocolate, } \\
\text { dinheiro, etc) }\end{array}$ & $\begin{array}{c}\text { Utilizar recompensas tangíveis } \\
\text { (exemplo: ingressos para o cinema, } \\
\text { doces, chocolate, dinheiro, etc) desde } \\
\text { que sejam dadas em momentos } \\
\text { específicos, de forma aleatória e com } \\
\text { pouca frequência. }\end{array}$ & 4 \\
\hline $\begin{array}{c}\mathrm{FS} . \\
1\end{array}$ & $\begin{array}{c}\text { Disponibilizar para o terapeuta métricas de } \\
\text { avaliação de desempenho de cada jogador ao } \\
\text { realizar uma determinada atividade (ex: número } \\
\text { de acertos/erros e tempo); }\end{array}$ & $\begin{array}{c}\text { Disponibilizar para o terapeuta } \\
\text { métricas desempenho (número de } \\
\text { acertos/erros e tempo) e formas de } \\
\text { observar quais e onde foram os erros } \\
\text { das crianças nas atividades. }\end{array}$ & 1 \\
\hline
\end{tabular}

Dentre os requisitos que tiveram a menor taxa de aceitação (abaixo dos $30 \%$, ou seja, teve mais de 6 recomendações de remoção), 4 fazem parte da classe "Navegação \& Interface", a exemplo dos requisitos Utilizar fontes do tipo Italic Serif e Utilizar mais imagens fotográficas do que ilustrações. A classe com a maior taxa de aceitação de requisitos $(87,5 \%)$ foi "Atividade" com apenas um requisito com taxa de aceitação de $90 \%$. Entre os requisitos nessa classe estão a criação de atividades para os pais interagirem com as crianças/jovens e atividades em que 
jogadores escrevam letras na tela com o dedo ou caneta. Outra classe com requisitos bem aceitos foi a de "Elementos de gamificação e motivação". Embora os requisitos dessa classe não tenham vindo nem da literatura especializada em SD e nem de software relacionados com SD, 8 de seus 11 requisitos foram aceitos integralmente entre os entrevistados. Alguns exemplos desses requisitos são os que abordam o uso de pontos, recompensas intangíveis, badges (insígnias) e conquistas, avatares e enredo/tema. Por outro lado, 2 requisitos dessa classe foram bastante questionados: o uso de recompensas tangíveis com 4 questionamentos - argumentou-se quais recompensas tangíveis podem ter o efeito contrário nos jogadores, fazendo-os só realizar as atividades em troca de recompensa - e o uso de leaderboards (quadro de líderes), com 5 questionamentos - com o argumento de que alguns jogadores ficariam desestimulados a realizar as atividades caso não ficassem bem colocados. Os demais requisitos que sofreram sugestão para remoção podem ser vistos na Tabela 4 . 
Tabela 4: Demais requisitos que sofreram pelo menos uma sugestão de exclusão do conjunto inicial

\begin{tabular}{|c|c|c|}
\hline ID & Descrição do requisito & $\begin{array}{l}\text { Recomenda } \\
\text { ções }\end{array}$ \\
\hline NI.5 & $\begin{array}{l}\text { Utilizar palavras estilizadas com elementos gráficos destacados (como estrelas no } \\
\text { fundo, setas, elementos coloridos). }\end{array}$ & 5 \\
\hline NI.6 & $\begin{array}{l}\text { Não utilizar decorações de fonte que alterem o formato da letra ou que possuam } \\
\text { contornos escurecidos e sombreamento. }\end{array}$ & 2 \\
\hline NI.7 & $\begin{array}{c}\text { Utilizar nas telas da aplicação cores de tons escuros como: cores azuladas, púrpuras e } \\
\text { cinzas. }\end{array}$ & 5 \\
\hline NI.8 & Quando a opção de alto contraste for selecionado, não utilizar somente cores primárias. & 1 \\
\hline NI.12 & Utilizar imagens de pessoas, principalmente, jovens e bonitas. & 8 \\
\hline NI.14 & Utilizar mais imagens fotográficas do que ilustrações. & 7 \\
\hline NI.15 & $\begin{array}{l}\text { Utilizar principalmente imagens de pessoas com a mesma idade ou mais velhas que as } \\
\text { crianças e adolescentes utilizando a aplicação. }\end{array}$ & 3 \\
\hline NI.22 & Utilizar sons de desenho animado (divertidos e exagerados). & 3 \\
\hline NI.25 & Os botões devem ter o fundo de cor escura e o texto de cor clara (alto contraste). & 1 \\
\hline NI.26 & $\begin{array}{l}\text { Utilizar botões em locais fixos e de fácil visualização. Evitar usar botões flutuantes } \\
\text { (botões ocultos por um menu). }\end{array}$ & 2 \\
\hline NI.29 & $\begin{array}{l}\text { Evitar o uso de frases condicionais (ex: "primeiro, clique nesse botão para depois clicar } \\
\text { naquele outro). É interessante dividir as instruções em etapas; }\end{array}$ & 1 \\
\hline NI.30 & Evitar o uso de menus suspensos, pois são difíceis para usuários com SD; & 1 \\
\hline FA.4 & Dar recompensas e elogiar os jogadores sempre que eles terminarem alguma atividade. & 1 \\
\hline S.1 & $\begin{array}{c}\text { Criar mecanismos que permitam as crianças interagir entre si dentro da aplicação, pode } \\
\text { ajudar a resolver o problema de isolamento e a encontrar amigos que possuam a mesma } \\
\text { idade. (Talvez, a troca e envios de presentes pela aplicação possam ajudar nessa } \\
\text { interação); }\end{array}$ & 1 \\
\hline A. 1 & $\begin{array}{l}\text { Criar atividades que permitam que as crianças sejam capazes de interagir com os } \\
\text { brinquedos que estão familiarizadas por meio do uso da câmera; }\end{array}$ & 1 \\
\hline EG.6 & $\begin{array}{l}\text { Criar um quadro de líderes (leaderboards), onde será ranqueado o desempenho de } \\
\text { todos os jogadores. Tem como principal função incentivar o clima de competição } \\
\text { amistosa entre os jogadores. }\end{array}$ & 5 \\
\hline EG.7 & $\begin{array}{l}\text { Criar um sistema de troca de presentes entre os jogadores. Abordagem para motivar a } \\
\text { interação amistosa e colaborativa. }\end{array}$ & 2 \\
\hline MC.2 & $\begin{array}{l}\text { As recompensas aos jogadores não devem ser restritas apenas à realização de } \\
\text { atividades como também a frequência com o que o usuário utiliza o aplicativo ou faz } \\
\text { atividades fora que não envolvem o aplicativo; }\end{array}$ & 1 \\
\hline MC.10 & $\begin{array}{l}\text { Permitir que jogadores sempre tenham acesso às instruções de como fazer as atividades } \\
\text { sempre que quiserem. }\end{array}$ & 1 \\
\hline FS.4 & $\begin{array}{l}\text { Permitir que o terapeuta possa avaliar de forma rápida quase instantânea as atividades } \\
\text { dos alunos. }\end{array}$ & 1 \\
\hline FS.5 & $\begin{array}{l}\text { Permitir que os terapeutas e pais atribuam recompensas aos jogadores quando acharem } \\
\text { necessário (ex: os jogadores receberem recompensas por bom comportamento) }\end{array}$ & 1 \\
\hline
\end{tabular}

No final da segunda fase, 16 novos requisitos foram adicionados ao conjunto inicial. Os novos requisitos puderam ser todos distribuídos entre as 8 classes iniciais, sem necessidade de se criarem novas classes. Exemplos desses novos requisitos são: utilizar as ferramentas de Inteligência Artificial para monitorar o desempenho de jogadores e ajustar o processo pedagógico (Ferramenta \& suporte) e utilizar vídeos para criar um contexto/background para alguma atividade (Mecânica de jogos \& configuração), como apresentado na Tabela 5. 
Tabela 5: Novos requisitos adicionados ao fim da segunda etapa

\begin{tabular}{|c|c|}
\hline Classe & Descrição do novo requisito \\
\hline \multirow{2}{*}{$\begin{array}{c}\text { Navegação e } \\
\text { Interface }\end{array}$} & Utilizar Animações nas palavras que devem ser destacadas \\
\hline & Utilizar cores fortes/brilhantes \\
\hline \multirow{3}{*}{ Entradas } & Possibilitar o uso de câmeras (celular ou webcam) \\
\hline & Possibilitar o uso do microfone \\
\hline & Utilizar joysticks (controle de vídeo game) \\
\hline $\begin{array}{l}\text { Feedback e } \\
\text { ajuda }\end{array}$ & Os lembretes/avisos/alertas devem possuir efeitos sonoros e visuais; \\
\hline \multirow{5}{*}{$\begin{array}{l}\text { Mecânica e } \\
\text { configuração }\end{array}$} & Colocar em evidência as atividades que os alunos tiveram um bom desempenho. \\
\hline & Utilizar vídeos para criar um contexto/background para alguma atividade. \\
\hline & $\begin{array}{l}\text { Atividades com os terapeutas devem ser mais focadas (sérias), já as atividades em casa } \\
\text { devem ser mais dinâmicas e motivacionais. }\end{array}$ \\
\hline & Permitir que o profissional passe atividades para casa por meio do aplicativo. \\
\hline & $\begin{array}{l}\text { O jogador deve poder continuar mesmo que não consiga terminar a atividade. Contudo, caso } \\
\text { ele não faça a atividade por completo ele não atingirá os } 100 \% \text { e com isso ganhará menos } \\
\text { pontos. }\end{array}$ \\
\hline \multirow{2}{*}{ Atividades } & Criar jogos que trabalhem o pensamento abstrato. Por exemplo, a carta enigmática \\
\hline & Criar atividades em que a criança deve gravar áudio sobre as figuras apresentadas. \\
\hline \multirow{3}{*}{$\begin{array}{l}\text { Ferramentas e } \\
\text { suporte }\end{array}$} & Criar ferramentas que possibilite colocar sons a imagens \\
\hline & $\begin{array}{l}\text { Criar um pacote de imagens e fundos temático como figuras com o tema de princesas, } \\
\text { dinossauros, carros, etc }\end{array}$ \\
\hline & $\begin{array}{l}\text { Utilizar Inteligência Artificial para monitorar o desempenho de jogadores na repetição de } \\
\text { tarefas para ajudá-los de modo mais eficiente }\end{array}$ \\
\hline
\end{tabular}

\subsection{Limitações e reflexões}

Ao analisar os dados apresentados na subseção anterior, é importante notar que as respostas dos entrevistados foram dadas em ambas as fases sem que eles experimentassem algum software, protótipo ou mockups (modelo digital usado para demonstrar funcionalidades) de um g-app SD implementado com os requisitos elicitados, uma vez que apenas uma iteração da metodologia foi concluída até agora. Desta forma, os atores-validadores tiveram que projetar possíveis benefícios e restrições dos requisitos sem usarem um g-app $S D$ real, com os requisitos implementados.

Tendo isso em vista, é possível entender porque alguns requisitos apresentados nesta lista preliminar que talvez pudessem ter sido aprovados unanimemente tenham recebido recomendações para a remoção, já que certos requisitos apresentam características e definições abstratas que podem ter causado dúvidas aos entrevistados e ficariam mais claros ao serem empregados em mockups ou protótipos. Isso também se aplica aos novos requisitos encontrados, já que alguns deles apresentam algumas ideias abstratas que, assim como os requisitos que receberam alguma recomendação para exclusão da lista, só ficarão mais claras com análises aprofundadas e iterações futuras com os validadores. Um bom exemplo disso, é o novo requisito encontrado "Utilizar cores brilhantes/fortes" que não deixa claro nem em quais partes da aplicação esse requisito deve ser empregado e nem quando, indicando a necessidade por novos estudos de validação.

Embora isso aconteça com os requisitos, é possível acreditar que o mesmo não aconteça com suas classes. Diferentemente dos requisitos contidos nelas, as classes, apesar de serem mais genéricas, são mais objetivas e menos abstratas. Dessa forma, é possível presumir que mesmo com a utilização de protótipos ou mockups de g-app $S D$, os resultados apresentados nos gráficos não sofram grandes alterações. Contudo, é importante ressaltar que nada impede que novas classes sejam criadas ou removidas em novos ciclos e interações da metodologia devido a outros fatores.

Por isso, a validação nesta seção é dito ser "de aparência" ou "de face" (Gravetter \& Forzano, 2012), já que traz um forte componente subjetivo embutido no julgamento. Devido a tal 
subjetividade e ao fato de a amostra de respostas vir de apenas $T_{\text {Atores }}=11$, adotaram-se intervalos de confiança de $90 \%$. A subjetividade embutida nestes resultados é minimizada usando-se na validação, especialistas no assunto, possibilitando estimativas coerentes com a realidade da alfabetização de jogadores com SD (Holden, 2010).

Um outro ponto importante, é o conceito de Design participativo. Como afirma Hecht \& Maass (2008), o objetivo do PD é dar voz aos usuários nas decisões sobre o design de seu ambiente de trabalho e ferramentas. Para tanto, o PD reúne diferentes clientes-atores e tenta fazê-los trabalhar juntos no processo de análise e de design de um sistema, permitindo que possam entender os pontos de vista um do outro e se beneficiar de seus conhecimentos. Embora na teoria essas ideias pareçam funcionar muito bem, na prática, como continua Hecht \& Maass (2008, tradução nossa), "muitas vezes existem barreiras sociais e de comunicação e desequilíbrio de poder entre os diferentes especialistas".

Neste trabalho, optou-se por restringir o desequilíbrio entre as opiniões dos atores-clientes, fazendo com que os pesos de suas opiniões fossem todos iguais, ao mesmo tempo em que se pudesse observar, de uma forma inicial, o quanto as barreiras sociais e culturais influenciariam o processo de validação e priorização das classes. Para tornar essa observação possível, foram selecionados especialistas do Brasil e da Austrália e ao coletar as suas opiniões sobre a importância das classes, foi possível constatar que com exceção da classe "Navegação e interface", as opiniões diferem entre si. Uma das possíveis causas disso, pode ter origem nas perspectivas do trabalho com SD, visto que enquanto os profissionais participantes no Brasil trabalham diretamente com pessoas com SD e, futuramente, serão usuários finais de g-apps SD, os profissionais participantes da Austrália trabalham de forma mais indireta, assumindo um papel de desenvolvedor (Designer) e cliente (pessoas com SD). Por isso, novos ciclos da metodologia devem ser realizados com adição de mais profissionais para verificar se as diferenças se mantém e também como elas devem afetar a engenharia de requisitos e desenvolvimento de g-apps SD.

\section{Conclusão e trabalhos futuros}

Este artigo apresentou requisitos para aplicativos de software gamificados para alfabetização de crianças com SD ( $g$-apps $S D$ ). O experimento de validação mostrou que as 8 classes com 76 requisitos inicialmente obtidos - a partir da revisão da literatura, da análise de produtos de software e das entrevistas com especialistas e pessoas com SD - são "úteis para que g-apps SD sejam profícuos e eficazes", segundo os 11 validadores. Além de comentar sobre os requisitos inicias, aceitando alguns como apresentados $(39 / 76)$, sugerindo ajustes $(16 / 76)$ ou recomendando somente a exclusão (21/76), os validadores acrescentaram outros 16. Devido aos poucos validadores e como a metodologia para elicitar requisitos recebeu apenas uma iteração, a validação é preliminar e exploratória, sendo formalmente, "de face".

A validação realizada sinaliza que o projeto de g-apps $S D$ é principalmente, uma tarefa de design de interfaces e de recursos de interação (Entradas), com aspectos lúdicos e socialização em posição secundária. É provável que isto se deva aos poucos usuários com SD na validação e à maior contribuição de profissionais e parentes que valorizem mais alfabetização e acessibilidade do que diversão. Maior presença de potenciais jogadores com SD na validação, principalmente adultos, que possam indicar suas preferencias lúdicas quando mais jovens, pode modificar esta sinalização.

Trabalhos futuros devem, além de priorizar os requisitos nas classes e realizar testes com $g$ apps $S D$ em funcionamento para verificar o aprendizado, tratar de validar os requisitos apresentados neste artigo mais extensivamente, incluindo, principalmente, pessoas com SD neste processo. Para isso, faz-se necessário a utilização de uma linguagem especial para realização dessa validação, uma vez que apresentar conceitos abstratos como requisitos para um público com SD 
não é uma tarefa trivial, tornando assim primordial a criação de um tipo de linguagem que possibilite explicar tais conceitos ao mesmo tempo que mantém esses usuários engajados no processo. Por fim, é possível afirmar que embora os resultados apresentados nesse artigo ainda sejam preliminares, eles já trazem indícios de que os requisitos serão mesmo úteis para alfabetização de crianças com SD.

\section{Referências}

Brandão, A., Brandão, L., Nascimento, G., Moreira, B., Vasconcelos, C. N., \& Clua, E. (2010, November). Jecripe: stimulating cognitive abilities of children with down syndrome in prescholar age using a game approach. In Proceedings of the 7th International Conference on Advances in Computer Entertainment Technology (pp. 15-18). ACM. doi: $\underline{10.1145 / 1971630.1971635}$ [GS Search].

Brandão, A., \& Joselli, M. (2015). Jecripe 2: estimulação da memória, atenção e sensibilização fonológica em crianças com Síndrome de Down. In Proceedings of the XIV Brazilian Symposium on Games and Digital Entertainment, SBGAMES (Vol. 15, pp. 518-525). [GS Search].

Buzzi, M. C., Buzzi, M., Perrone, E., Rapisarda, B., \& Senette, C. (2016, April). Learning games for the cognitively impaired people. In Proceedings of the 13th Web for All Conference (p. 30). ACM. doi: 10.1145/2899475.2899487 [GS Search].

Campigotto, R., McEwen, R., \& Epp, C. D. (2013). Especially social: Exploring the use of an iOS application in special needs classrooms. Computers \& Education, 60(1), 74-86. [GS Search].

Caponetto, I., Earp, J., \& Ott, M. (2014, October). Gamification and education: A literature review. In European Conference on Games Based Learning (Vol. 1, p. 50). Academic Conferences International Limited. [GS Search].

Colpani, R., \& Homem, M. R. P. (2015, July). An innovative augmented reality educational framework with gamification to assist the learning process of children with intellectual disabilities. In Information, Intelligence, Systems and Applications (IISA), 2015 6th International Conference on (pp. 1-6). IEEE. [GS Search].

Cunningham, C. (2008). Síndrome de down: Uma introdução para pais e cuidadores. Artmed. [ $\underline{G S}$ Search].

de Souza, I., Moura, A., \& Ghirello-Pires, C. (2017, October). Requisitos para Aplicações Gamificadas e de Realidade Alternada para Alfabetização e Aquisição da Linguagem em Crianças com Síndrome de Down. In Brazilian Symposium on Computers in Education (Simpósio Brasileiro de Informática na Educação-SBIE) (Vol. 28, No. 1, p. 867). DOI: 10.5753/cbie.sbie.2017.867. [GS Search].

Camargo, L., \& Fazani, A. (2014). Explorando o Design Participativo como Prática de Desenvolvimento de Sistemas de Informação. InCID: Revista De Ciência Da Informação E Documentação, 5(1), 138-150. doi: 10.11606/issn.2178-2075.v5i1p138-150. [GS Search].

Farias, E. H., da Silva Hounsell, M., Blume, L. B., Ott, F. R., \& Cordovil, F. V. P. (2013). Moviletrando: Jogo de movimentos para alfabetizar crianças com down. In Brazilian Symposium on Computers in Education (Simpósio Brasileiro de Informática na EducaçãoSBIE) (Vol. 24, No. 1, p. 316). [GS Search].

Feng, J., Lazar, J., Kumin, L., \& Ozok, A. (2008, October). Computer usage by young individuals with down syndrome: an exploratory study. In Proceedings of the 10th international ACM 
SIGACCESS conference on Computers and accessibility (pp. 35-42). doi: $\underline{10.1145 / 1414471.1414480}$ ACM. [GS Search].

Fernández-LóPez, Á., RodríGuez-FóRtiz, M. J., RodríGuez-Almendros, M. L., \& MartíNezSegura, M. J. (2013). Mobile learning technology based on iOS devices to support students with special education needs. Computers \& Education, 61, 77-90. [GS Search].

Ghirello-Pires, C. S. A. Algumas questões sobre a linguagem oral de crianças com síndrome de down. Comunicações, 23(3), 259-273. [GS Search].

Gravetter, F. J. "Forzano LAB. (2012). Research Methods for the Behavioral Sciences. 4th edn. Belmont, CA: Wadsworth 78. [GS Search]

Haro, B. P. M., Santana, P. C., \& Magaña, M. A. (2012, October). Developing reading skills in children with Down syndrome through tangible interfaces. In Proceedings of the 4th Mexican Conference on Human-Computer Interaction (pp. 28-34). ACM. [GS Search].

Hecht, K. M., \& Maass, S. (2008). Teaching participatory design. In Proceedings of the Tenth Anniversary Conference on Participatory Design 2008 (pp. 166-169). Indiana University. [GS Search].

Holden, R. R. (2010). Face validity. Corsini Encyclopedia of Psychology. [GS Search].

Jadan-Guerrero, J., Jaen, J., Carpio, M. A., \& Guerrero, L. A. (2015, June). Kiteracy: a kit of tangible objects to strengthen literacy skills in children with down syndrome. In Proceedings of the 14th International Conference on Interaction Design and Children (pp. 315-318). doi: $\underline{10.1145 / 2771839.2771905}$ ACM. [GS Search].

Larman, C. (2004). Agile and iterative development: a manager's guide. Addison-Wesley Professional. [GS Search].

Martin, G. E., Klusek, J., Estigarribia, B., \& Roberts, J. E. (2009). Language characteristics of individuals with Down syndrome. Topics in language disorders, 29(2), 112. [GS Search].

Mothu, A (2017, february), Disponível em: https://medium.theuxblog.com/participatory-designtools-and-methods-741543b1ff5b

Pohl, K. (2010). Requirements engineering: fundamentals, principles, and techniques. Springer Publishing Company, Incorporated. [GS Search].

Roberts, J. E., Price, J., \& Malkin, C. (2007). Language and communication development in Down syndrome. Developmental Disabilities Research Reviews, 13(1), 26-35. [GS Search].

Schwartzman, J. S. (1999). Síndrome de Down. São Paulo: Mackenzie, 44-81. [GS Search].

Shih, T. K., Squire, K. and Lau, R. W. (2010). Guest editorial: special section on game-based learning. IEEE Transactions on Learning Technologies, 3(4), 278-280. [GS Search] 